\title{
الشيخ الغزالي كما عرفته في الجزائر
}

*عمار الطالبي

بدأت صلتي بشيخنا محمد الغزالي رحمة الله عليه في الستينات، زرته في بيته مع زميلين في الدراسة، ثم زرته مرة أخرى وهو مسؤول في وزارة الأوقاف، وكان فرع اتحاد الطلبة المسلمين الجزائريين بالقاهرة قد كلفني بالحصول على مجموعة من الكتب لإنشاء مكتبة لهذا الفرع. ومضت سنوات على استقلال الجزائر، وكان أن دعي الشيخ محمد الغزالي للخور ملتقيات الفكر الإسلامي التي كانت تنعقد سنوياً في الجزائر، فكانت له صولات وجولات فيما يلقيه من كلمات بليغة، وفيما يناقشه من قضايا المسلمين. في أحد الملتقيات أبرق إليه ابنه بألا يعود إلى مصر لأن الرئيس السادات سيلقي به في السجن، وكان قد حضر الرئيس ابن جديد زائراً ذلك الملتقى في ختام أعماله، فأبلغه وزير الشؤون الدينية في ذلك العهد الشيخ عبد الرحمن شيبان هذذا الخبر، فسلم ابن جديد على الشيخ الغزالي وقال له: الجزائر بلدك، فمرحباً بك داعية إلى الإسلام فيها.

وكانت إذ ذاك المساعي حثيثة لإنشاء جامعة للعلوم الإسلامية في الجزائر. وعلى الرغم مما وجدناه من

صدود وعراقيل من عناصر ماركسية ماكرة، ويسارية كائدة، فإن ابن جديد آتاه الله رشده، فأصدر مرسوماً بإنشاء هذه الجامعة، وكان حريصاً أشد الحرص على أن يكون الشيخ الغزالي من مؤسسيها، وكان الشيخ الغزالي في ذلك الوقت أستاذاً زائراً في جامعة الأمير عبد القادر للعلوم الإسلامية. وقدم وفد من الجزائر لهذا الغرض -كنت من بين أعضائه مع الأخوين: عبد الوهاب حمودة، وابن عبّو - إلى قطر؛ ويشاء الله أن يحضر الشيخ محمد الغزالي حفل افتتاح الجامعة بمدينة قسنطينة سنة 1404هـ/1948م، وكان حفلاً كبيراً حضره رئيس الدولة وعدد كبير من الوزراء وكبار المسؤولين ووالي قسنطينة، وسفراء الدول الإسلامية. وكان الشيخ الغزالي أول المستَقبلين، وكان قد تولى رئاسة المجلي العلمي لهذه الجامعة وتوليت إدارتا، فاستبشر الناس 
بوجود الشيخ لما عرفوا من علمه ودعوته وفضله، خلال ملتقيات الفكر الإسلامي التي كانت تذاع محاضراتا

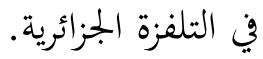

أقام الشيخ الغزالي أول الأمر في فندق "بانوراما" بمدينة قسنطينة، ثم انتقل إلى منزل (فيلا) فأصبح جاراً لي، وسعدت أسرتي بجواره كما سعدت، ونعم الجوار جواره، يعمل وكله نشاط وحيوية ويسبقني أحياناً إلى الجامعة مبكراً ويفضل أحياناً أخرى أن يتجه إلى الجامعة راجلاً للارتياض، ولم تكن المسافة بين بيته وبينها بعيدة.

واختار الشيخ لنفسه أن يدرس تفسير القرن الكريم، وكنا أوصينا طلبة الجامعة أن يعودوا إلى تفسير العلامة الشيخ محمد الطاهر بن عاشور (التحيم والثنوير) مرجعاً لهم، فاطلع على هذا التفسير، وقراً منه وأعجب به، وأعتقد أنه قرأه لأول مرة، كما اطلع على كتابه مقاصد الثريعة، ولفت نظره أن ابن عاشور أضاف إلى مقاصد الشريعة مقصد "الحرية".

وصار في هذه الجامعة موجهاً وأستاذاً، ومفتياً، يزوره الناس للفتوى في الجامعة وفي بيته. ومن أهم أماله في الجامعة وخارجها (لا أريد أن أتعرض للتفاصيل كي لا يطول الحديث) الدعوة إلى الله، وتحليل قضايا المسلمين، ونقد ما يعانون من أمراض ومآسِ، وأصبح الناس ينتظرون حديث الأسبوعي الذي يلقيه في التلفزة يوم الاثنين، يستمع إليه جمهور الناس، ويفهمونه في مختلف أرجاء البلاد لسهولة عبارته، ووضح فكرته، وصدق لهجته، وحسن استشهاده بالقرآن الكريم الذي يجري على لسانه بيسر واضح، فتفهمه الجماهير بفطرتا لأنه يخاطبها في أعماقها وينفذ إلى أعماق قلوبها، كما كان يلقي في قسنطينة كل يوم جمعة تقريباً درساً في أحد مساجدها الجامعة، وغالباً ما يكون في التفسير الموضوعي لسورة من السور، ينزها على لئ أوضاع المسلمين قديماً وحديثاً، يعرض مفاصلها ووحدات موضوعها عرضاً موجزاً لكنه مستوعب، فتصبح بذلك السورة صورة شمسية، كما يقول، معروضة أمام عينيه، يفصل القول في موضوعها فيرسم بذلك وحدة متكاملة متناسقة، ما يظنه بعض الناس أشتاتاً أو أجزاءاً مفككة.

وكان يفعل هذا أيضاً في جولات يُدعى فيها إلى ولايات أخرى في الجزائر غير ولاية قسنطينة، يتنافس الناس فيها على دعوته لإلقاء درس أو موعظة أو محاضرة. وقد سافرت بصحبته إلى عدة ولايات في أعماق 
الجزائر، في الصحراء وغيرها، وكان لا يرد دعوة وإن شق عليها لسفر أحياناً، وهو في شيخوخته تحسبه شاباً في عزمه وتوكله، ينتقل أحياناً بالسيارة مسافات بعيدة، وأخرى بالطائرة ثم السيارة، وهو في ذلك كله يشعر بسعادة غامرة في دعوته إلى الله، وفي لقائه مع المؤمنين شباباً وشيوخاً، نساءً ورجالاً. بهذا وصل ما انقطع من دعوة الإمام ابن باديس والشيخ الإبراهيمي وغيرها من رجال الدعوة والتجديد الذين دعوا في الجزائر وغيرها إلى النهضة والوعي، وجاهدوا في الله حق جهاده، وحَسِبَ الناسُ أن ابن باديس قد بعث، وأن الإبراهيمي قد عاد.

ومن الأحداث التي شهدها أول مرة في حياته زلزال هز مدينة قسنطينة، فخرج من بيته فزعاً وكان الزلزال قد حدث بعد المغرب، ولم ينس أن يعبر عن هذه الواقعة في تفسيره قائلاً: "وقد شهدت زلزالاً لم يستغرق نصف دقيقة كدنا نفقد فيه وعينا". 1كما أشار إلى ذلك في تفسيره لسورة الزلزلة: "وقد عاينت زلزالاً

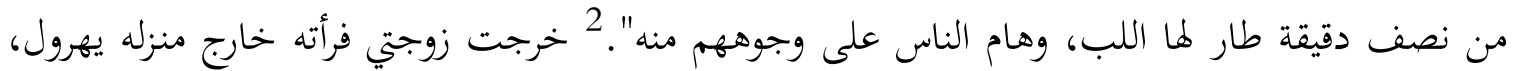
فسألته عن حاله، فقال: اطمئني لا شر إن شاء الله، وأثّر هذا في نفسه، فألقى حديثاً في التلفزة حول هذا الموضوع، وعتب على الناس مبالغتهم في الهلع، والخروج من ديارهم هائمين، يبيتون خارجها عدة ليال. ولا أنسى موقفاً اغرورقت فيه عيناه بالدموع، وشهق شهقة عميقة لما أن زرنا مدينة خنشلة المشهورة بحمَّامها المعدني الطبيعي. وقمنا بزيارة مقبرة الشهداء، وكانت قصتها عجيبة، إذ عُثر على حفرة هائلة ألقى ردى الاستعمار الفرنسي فيها جثث ألف شهيد بقيودهم وأغلالهم ولباسهم وأحذيتهم، فُنقلوا ودُفنوا في مقبرة فيها ألف قبر لألف شهيد تقع المدينة المشار إليها في منطقة الأوراس المجاهدة، وذلك بعد الاستقلال. وقد عانى شيخنا من عنت جهلة المتدينين وأنصاف المتعلمين وفتيان السوء3 -كما يسميهم - ممن يتطاول على الأمة في الدفاع عن أحاديث لا يفهمون مرماها، وقد تكون من أوهى المرويات وأضعفها. وكان يفد إليه ويجلي في مجلسه في الدرس أصناف من هؤلاء ممن يفتون بسقوط الزكاة في عروض التجارة، ويزعمون

$$
\begin{aligned}
& 2 \\
& 3
\end{aligned}
$$


أغم من أهل الحديث وأنصار السنة، وقد أشار إلى ذلك في أحد مؤلفاته الذي دعاه إلى تأليفه في الجزائر أمثال هؤلاء: "وقد ظهرت في الجزائر فتوى لواحد من أهل الحديث حاربناها بقوة قبل أن تصيب الإسلام وأهله بضر شديد... فكيف يزعم زاعم أن عروض التجارة لا زكاة فيها؟! وأين يذهب بقوله تعالى: ولهِيًا أيَّهَا

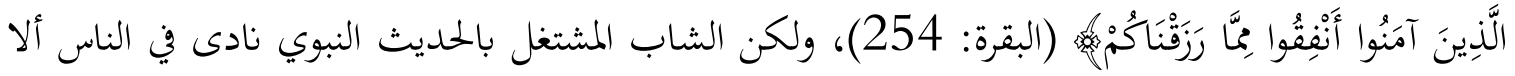
زكاة في عروض التجارة، إلا أصل لها فيما قرأ...". لذلك كله نجده يعنف في الرد على أمثال هؤلاء الذين لا يتدبرون القرآن، ولا طبيعة الدنيا التي نعيش فيها، فإنه لا فقه مع العجز عن فهم القرآن، وفهم الحياة، إذ كرك يختطف أحدهم حكما من حديث منفرد فيشقي البلاد والعباد.5 5

وقد سأله طالب وهو في الجزائر: أصحيح أن موسى عليه السلام فقأ عين ملك الموت عندما جاء لقبض روحه؟ ففكر في الحديث وراجعه في مصادره، وقرر أنه معلول المتن بعلة قادحة، وأنه لا داعي للدفاع عنه، وإن صح سنده، كما فعل الإمام المازري.

ووقعت له نادرة أخرى في الجزائر، أتاه رجل طويل القامة، ضخم الجسم، فقال له: "إنه مسكون... قلت: من يسكنك؟ قال جني عات غلبني على أمري، فقلت وأنا أضحك: لماذا لم تسكنه أنت؟ إنك رجل طويل عريض، فسكت حائراً". 7 وأنقل هنا عبارة له تدل على ضجره الشديد بأمثال هذه الظواهر في المجتمع الإسلامي: "قلت وأنا ضجر: هل العفاريت متخصصة في ركوب المسلمين وحدهم؟! لماذا لم يشكُ ألماني أو ياباني من احتلال الجن لأجسامهما؟ إن سمعة الدين ساءت من شيوع هذه الأوهام بين المثدينين وحدهم"، 8 ولم يأت الشيخ في هذا الإنكار ببدع من القول، فقد حارب المعتزلة وغيرهم من العلماء من قبله هذا ورفضوه. وأغلب ما كتبه وأشار إليه في كتاب السنة النبوية قصة عليَّ في أحاديث جرت بينا قبل أن يسطرها في كتاب، بل إنه ألقى حديثاً في التلفزة في هذا الإسكان الجني في أجسام البشر.

\begin{tabular}{rr}
\hline & 4 \\
& \\
& \\
& \\
\hline 25 &
\end{tabular}


وقد سعدت أيّما سعادة في صحبته في أسفار كثيرة كما أشرت، داخل الجزائر وخارجها، منها سفرنا لحضور مؤتمر المجمع لملكي لبحوث الحضارة الإسلامية بعمان (الأردن) مرتين، مررنا على روما، وبتنا بهذه العاصمة التاريخية، فكان نعم الصاحب في السفر ونعم الملتزم بالأوقات في حله وترحاله، يؤنسك بنكاته ونوادره، ويجعلك لا تشعر بالمسافات في صحبته.

وأشاع المشتغلون بالمرويات الواهية وفروع الفقه بلا فهم في أوساط طلاب الجامعة أن منهاج الجامعة الدراسي مقصود به مضادة الشريعة ومضايقتها، لما أن وجد من بين مواد الدراسة مداخل للعلوم البيولوجية والفيزيائية قصد منها أن يكون للطالب تكوين علمي عام.

وأذاعوا أن منهاج الجامعة أخذ من جامعة السوربون، وأها لا هتم بالعلوم الشرعية بقدر ما تهتم بالعلوم البعيدة عن الشرع، كما أشاعوا أن الجامعة بها جواسيس تابعون للموساد، لأننا جعلنا من بين موادها دراسة اللغة العبرية لمن يتخصص في مقارنة الأديان، يختار بينها وبين اللغة اليونانية، فاستغربوا ذلك، لأفم يتصورون أن هذه الجامعة تقتصر على دراسة الفقه المالكي من مختصر الشيخ خليل وشروحه أو مؤلفات الشيخ الدردير لا تتجاوز ذلك، ولا تعدو أن تكون "زاوية" على النمط القديم.

كما كان في الجزائر فريق من الناس يرون أن الجامعة قنبلة مؤقتة، وأها خطر داهم، وهم الذين يحقدون على الإسلام ويمكرون به، فوجدوا سبيلاً إلى نسف الجامعة في مثل هذه العقليات الغبية المتحجرة، ولم يسلم الشيخ الغزالي من أن يهتم بعد ذلك بأنه هو السبب فيما يدور في الجزائر من مشكلات، اتممه بذلك أحد كبار المسؤولين، بل أكبرهم، في وقت من الأوقات، وصرح بذلك في القاهرة في جمع من اليساريين من يحترف الكتابة والإعلام والثقافة.

أوعز هؤلاء الذين يريدون هدم هذه الجامعة لأولئك الذين ضاقوا ذرعاً بمنهجها وبمضايقة العلوم الكونية في نظرهم للعلوم الشرعية، ليقوموا ضدها، ويحاربوا إدارتا التي عزمت على أن تقيم قبة فلكية، وكنا فعلاً اتفقنا مع شركة، ورصدت لذلك ميزانية لبناء هذه القبة، وإنشاء معهد للتراث الفلكي الإسلامي، ولدراسة العلم الفلكي الذي أهمله الجامعات الأخرى في الجزائر، فأثاروا الشغب حولها، وساعدهم الوالي على ذلك الذي صادف هواه في كره هذه الجامعة والحقد عليها. 
وكان الشيخ الغزالي رحمه الله في ذلك الوقت قد تعب لما أصابه من جلطة في دمه، كما أصابه وصب

وضير من اختلاف هذه الجماعات خارج الجامعة، وتنازعها، كل جمع منهم يريد أن يسيطر على الجامعة بما له من بعض الأتباع من الطلبة، وضاق عليه أمره، وشعر بأس شديد، فأفسدوا على الجامعة أمرها ودخلوا مكتب المدير، واحتلوه، وحلا لهم الجلوس فيه والأكل. وفي هذه الفتنة وجد خصوم الجامعة ضالتهم، وحدث قبل ذلك أن زارت الشيخ ابنته حرم الأستاذ محمد عبد القدوس، وشعرت بما فيه أبوها من ضيق وقلق، وما أصابه من جلطة في دمه، فألحت عليه العودة إلى القاهرة، وإن كان في نفسه عازماً على المضي في سبيل المناضلة والدعوة، فكتب خطاباً لوزير الشؤون الدينية يعتذر فيه عن الاستمرار، وكنت أخبرت وزير التعليم العالي بالأمر، وألححت عليه أن يكتب خطاباً للشيخ يرجوه الاستمرار في عمله حتى لا يجد الخصوم منفذاً

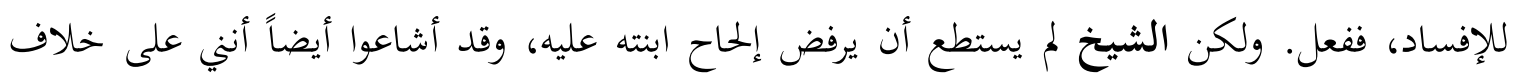
شديد مع الشيخ الغزالي، وأني ضايقته، وفرضت عليه المناهج الدراسية التي استقيتها من جامعة السوربون الكافرة كما أشرت إلى ذلك من قبل.

وتظاهر الوالي بإقامة حفل توديع للشيخ، وأغرب شيء أنه أعطى الكلمة لهؤلاء الطلبة الذين عبثوا بالجامعة في هذا الحفل، ومنعني من الكلام لأودع شيخنا وأنا في غاية الحزن من أن أمنع من ذلك، وأنا الذي صحبته وعملنا سوياً طوال خمس سنوات بما فيها من سمان وعجاف، وأنا مدير لهذه المؤسسة الرسمية، فانظر سئر سئرس وأعجب من سلوك الحاقدين المستبدين!!

وهكذا غادر الشيخ الجامعة بعد خمس سنوات من العمل الدؤوب من سنة 1984م إلى سنة 1989م، وكان ذلك آخر عهد له بهذه الجامعة، ثم غادرها من بعده أيضاً مكرهاً، بعد أن نصّب وزير التعليم العالي في ذلك الوقت لجنة من أنصاف المتعلمين تشرف على الجامعة، ثم أقالني من هذا المنصب غير المأسوف عليه. وبعد مدة خالفني الدكتور أحمد عروة رحمه الله، فعانى من أولئك النفر ما عانى، وذاق ألواناً من العسف والضيق إلى أن توفاه الله إليه، وأصبحت الجامعة اليوم شبه زاوية كما كانوا يحلمون، وهكذا الصبيانية الدينية تذبح نفسها بنفسها وتدمر ذاتما بسعيها إلى حتفها بظلفها. 
وأثناء وجودنا - ولله الحمد- استطعنا أن ننشئ فروعاً للجامعة، منها معهد اللغة العربية والحضارة

الإسلامية بوهران في غربي الجزائر، ومعهد الشريعة بباتنة في منطقة الأوراس، ومعهد آخر في أعماق الصحراء في أدرار في الجنوب الغربي من الجزائر، بالإضافة إلى معهد أصول الدين في الجزائر العاصمة الذي أنشئ قبل جامعة الأمير عبد القادر تابعاً لجامعة الجزائر سنة 1982م. وكنا على وشك أن نفتح معهداً آخر في "عزابة" شمال شرقي قسنطينة، ولكن لما بدأ شغب المشاغبين يهدد الجامعة، أخبرين وزير التعليم العالي أنه قرر عدم فتح هذا المعهد بعد أن وافق عليه، بسبب الذي حدث، فأوقف ذلك، مع أنه كان يشرف على بناء هذا المعهد وإعداده من أموال التبرعات الشعبية الرائد علي بومنجل ذكره الله بالخير إن كان ما يزال على قيد الحياة، وهو أحد المجاهدين المعروفين بمحاربته للاحتلال الفرنسي، كان رئيس جمعية محلية أسست لهذا الغرض فخاب أمل الجمعية وأمل هذا المجاهد، ولم يتحقق منه شيء إلى يومنا هذا.

والآن يمكن لي أن أشير إلى بعض السمات البارزة التي اتضحت لي من تعاملي مع الغزالي ومن الحديث معه ومن قراءتي له. إنه كاتب يستعمل عقله، وإن للعقل عنده مكانة متميزة، ولا يسمح لنفسه أن يأخذ بما يخالف العقل، وهذا ا/ر في غاية الوضوح فيما يتحدث به وفيما يكتب. يقول: "إني بعقلي أدركت أن للكون سيداً أبدعه، ودبر أمره، وأيقنت أن هذا السيد واحد لا اثنان لا ثلاثة...". هذا في أصل العقيدة نفسها فما بالك بغير ذلك، وأنا لا أشك أن مثل هذا الاعتزاز بالعقل والسمو به وتحكيمه في الأمور كلها إنما هو ناشئ من شخصيته التي رباها القرآن، ومن تلاوته له تلاوة واعية، وتدبرها لمعانيه، وهذا ما جعله يعبر عن ذلك بأنه: "ليس في تاريخ الثقافة الإنسانية كتاب ينشئ العقل المؤمن إنشاء، ويعرض آيات الله في الأنفس والآفاق لتكون ينابيع فكر يتعرف على الله، ويستريح ؛إلى عظمته كما وقع في هذا القرآن" 10 بل إنه جعل: "التفكير الواعي العميق أساس هذه الرسالة، سواء فكر المرء وحده أم استعان بأصدقائه، المهم أن

$$
\begin{aligned}
& 9 \text { 9 } 9 \\
& 10
\end{aligned}
$$


يستيظ العقل النائم فيرى آيات ربه في آفاق العالم..."، 11 ويرى "أن التفكير خاصة العقل الحي، وسمة الإنسان الراشد، وكل تدين ينبو عن منطق العقل ويرفض حقيقة الفطرة، فهو لغو من عند الناس، وليس وحياً من عند الله سبحانه"،12 بل إن "ما خالف العقل لا يكون ديناً ولبعض الناس مرويات لا إسناد لها يجعلوها ديناً وما هي بدين"، 13 كما أن الدين عنده من جهة أخرى: "علم مقطوع به، والوحي حصانة لمقل وضمانة لأحكامه".

ولكن مع هذا كله فهو يعرف حدود العقل وطاقته: "وطمحت أفكاري إلى حد فوق طاقتها فتساءلت عن هذا العرش والاستواء؟ وكان الجواب: إن الذي يجهل ما تحت قدمه لا يصلح له التطاول، خير لك أن تعرف لماذا وجدت، وأن تحقق الحكمة من وجودك، فهذا أولى بك هوَوَهُوَ الَّذِي خَلَقَ السَّمَاوَاتِ

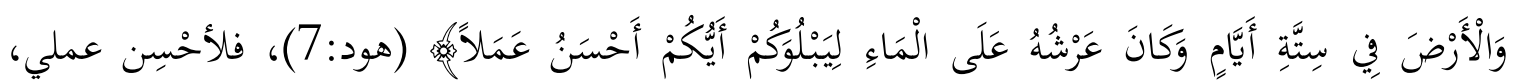
ولأصْقِل عقلي، ولأزكي نفسي، ولأحقق ثمرة وجودي، فهذا أولى بي، وأجدى عليّ". 15 وكثيراً ما ينعى على المسلمين، ويقد مسالكهم، ويكزنه جهلهم بالكون في عصرنا هذا: "والحزن أن العقل الإسلامي الآن جهول بالكون، تائه عن قوانينه، ضعيف الخبرة بها، والقدرة على استغلالها... والمفروض أن العقل المؤمن أخبر بالحياة، وأذكى في الكون من العقل الملحد، لأن الإيمان بالله يقوم في الإسلام على تأمل للكون، ووعي بآيات الله في آفاقه، إنه لشيء يثير الحزن والقلق أن نجد المسلمين في مؤخرة القافلة البشرية على النحو الذي يقول فيه الشاعر:

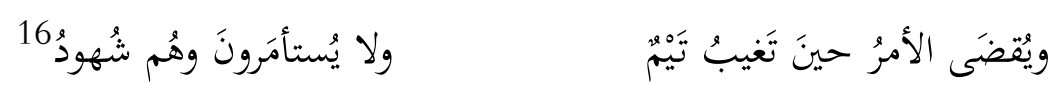

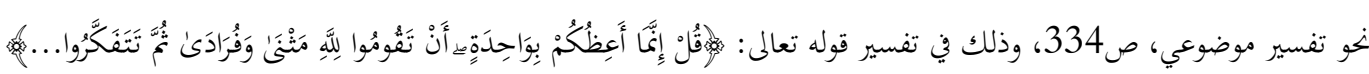

12

$$
\begin{aligned}
& 13 \\
& 15 \\
& 16
\end{aligned}
$$


وهو يطبق هذه السمة التي اكتسبها من توجيه القرآن، فأصبحت فيه سجية راسخة، تطبيقاً واضحاً

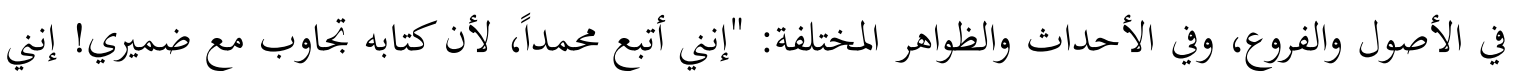
عرفت الله بعقلي بعدما نظرت في نفسي، وفي آفاق العالم الذي يضمّني وسائر البشر"، 17 وذلك لأل الأن: "الإيمان الذي يقوم على تخدير العقل، أو تمويته، لا وزن له، ولا خير فيه، ولكن جماهير غفيرة تنحّي العقل

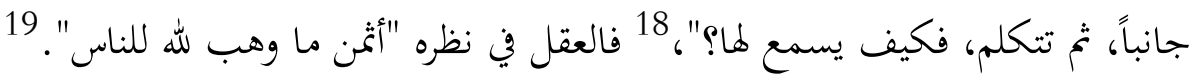
ونغتم متمته العقلية هذه التي صبغت منهجه في أحاديثه وكتاباته بعتاب له، يعتب فيه على أسلافنا في هذا المجال: "وقد عاتبت أسلافنا على هجرهم للفلسفة القرآنية الدراسة للمادة، وانشغالمم بالفلسفة اليونانية الباحثة في التصورات والأوهام، وإن كان من آبائنا من سذّ هذه الخلة، لكنهم للأسف قلّة". 20 وأعترف أني قد استفدت منه هذا الجانب فن نظريّ للقرآن، ولأحاديث وخاصة الواهي منها، فاسترحت مما أجده في نفسي منها في قراءئ لبعض نصوص الأحاديث من هذا القبيل، في مجالس كثيرة بتري بينا فيها أحاديث في هذا الموضوع. وعلى الرغم من اشتغلاي بالفلسفة فإني كنت أتوقف عندها، وأتخذ لنفسي فيها مذهب الوقف، حتى أزال عني هذه الغشاوة فصرت إلى ما صار إليه من وضوح في الرؤية إزاء ذلك كله.

وهناك سمة أخرى خحتها في أحاديثه وكتاباته وهي أنه يتساءل، ويلاحظ، ويتأمل، فهو يمتاز بدقة الملاحظة في الظواهر الاجتماعية والسياسية والاقتصادية وبتأملاته في ظواهر الكون التي تثير انتباهه، وتفسيره للقرآن، وأحاديثه مليئة هذا: "إن غزاة الجو -وهم في الطريق إلى القمر - نظروا إلى الأرض وهم على بعد

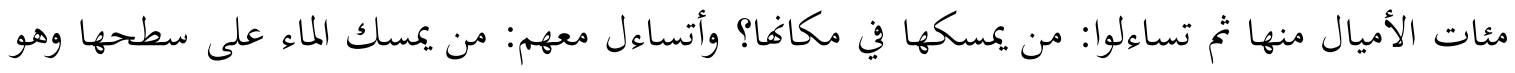

17
19
20


أربعة أخماس الكرة؟ لماذا لا ينسكب في الجو؟ لأن الله جعل الأرض كفاتا، 21 تحذب كل قطرة إليها، أيّ لطافة سارية في طباق البر والبحر تقوم هذا الصنع الباهر؟". 22

وهو في ملاحظاته أيضاً يتابع برامج عالم الحيوان والبحار في التلفزة، ويتأمل ويعجب: "إنني أتابع برامج عالم الحيوان وعالم البحار، وأعجب كيف تتكاثر الأحياء، وكيف تتفانن، وكيف يجعل الله طعام طير سارح من دودة ملصقة بظهر حيوان ضخم، يستريح حين يأكلها هذا الطير!!"، 23 ويرمق هذه الظواهر الطبيعية وهو في الطائرة مسافراً، تجوب أجواء الصحراء أو البراري والجبال، وتقطع ركام السحاب في شثمال الجزائر وجنوبها، ويسبح الله حين يلحظ جبالاً من السحاب المركوم، تعلوها الطائرة، فيرى السحب تحتها. وهو لا يستنكف أن يأخذ معلومات علمية عن راديو أثناء استماعه له، وينقلها في تفسيره إذا كان مصدر الحديث موثوقاً به علميّاً.

ومن أهم ما استفلت منه شخصياً، وأفاد منه جمهوره في الجزائر، ومن يحبون أن يأخذوا عنه من المتنورين، طريقته في التفسير الذي نحا فيه نواً جديداً، وسبيلاً ليسلكه من كان قبله في تفهيم القرآن، وقد عبر عن ذلك هو نفسه -كما فعل ابن خلدون في المقدمة في إنشائه لعلم جديد، هو علم الاجتماع البشري- عبّر عن ذلك في صدر تفسيره قائلاً: "هذه دراسة جديدة للقرآن الكريم... قد أرتاد طريقاً لم أسبق إليه، أفتح به باباً من أبواب الخير"،25 وميّز في ذلك بين التفسير الموضوعي والتفسير "الموضعي" أو التحليلي، والتفسير الموضوعي قد يكون هدفه تفسير الوحدة الموضوعية لكل سورة على حدة، وقد يكون تفسيراً لوحدة موضوعية معينة، من خلال القرآن كله، تتبعاً واستقراء.

$$
22 \text { 22 } 2123
$$


وهذا الارتباط الحميم بالقرآن ليس شيئاً جديداً طارئاً على حياته، بل إنه لزمه منذ طفولته، وتشربه قلبه منذ نعومة أظفاره: "لقد صحبت القرآن من طفولتي وحفظته في سن العاشرة، ومازلت أقرأه وأنه في

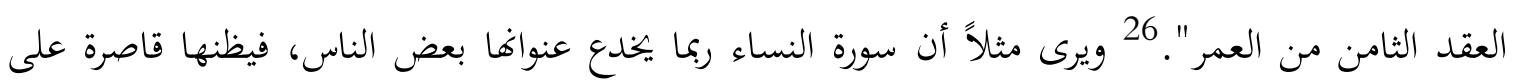
شؤون المرأة فيقول: "وقصار النظر يحسبون السورة أجزاء مفككة، وهذا خطأ يحمي الله منه أهل التدبر والاعتبار"، 27 ثم يبيّن "أن موضوع السورة عام، يتناول المجتمع كله... فحديث النساء جزء من كل"، 28 وهو في ذلك يصور القرآن ومعانيه تصويراً جميلاً متناسقاً: "إن معاني القرآن متداخلة متضافرة تلتقي كلها في سياق واحد، يعمل عمله في النفس، وليست هدايات القرآن فصولاً مقسمة على نحو متميز، وهكذا العالم نراه مصدراً لأشتات العلم، وهو كيان واحد، يستقي منه علماء الأحياء، وعلماء طبقات الأرض وعلماء الفلك...". 29 وهذه المقابلة بين آيات القرآن ومعانيه، وآيات الأكوان وتناسقها وغناها، لم يسبق إليه فيما أعلم. ويصف تتابع معاني سورة الأعراف مثلا بأها: "مع بدء السورة بدأت عدة معان مجملة، أخذت تتسع كأها رؤوس مثلثات تضمّنت قواعدها تفاصيل شتى، على أن هذه المعاني لا تسير في تيارات منفصلة، بل تراها وهي تتلاقى، كأها ضفائر متناسقة، هدفها جميعاً الإيمان، والعبرة، والاستقامة والوعي"، 30 ولكنه يعود فيصف سورة يس، بأفا ذات مقدمة وثلاثة فصول، 31 فكل سورة لما معانيها ونسقها وهدفها الرئيس.

وقد يسأل سائل: هل كان الشيخ بدعاً في تفسيره؟ وهل تأثر بقراءاته لتفاسير غيره؟ وإذا أراد أن يستأنس بغيره في معنى من المعاني أو في سياق من السياقات هل يشير إلى ذلك؟ تساءلت هذا السؤال فرأيته يذكر في تفسيره الشيخ رشيد رضا، ويستفتيه : "وبعد إعمال الذهن وإدامة التدبر لم أعد بطائل فقلت أستفتي صاحب المنار، وأتعرف على رأي الأستاذ الإمام، فوجدت الجواب السائغ"، 32 ونقل عنه أيضاً في

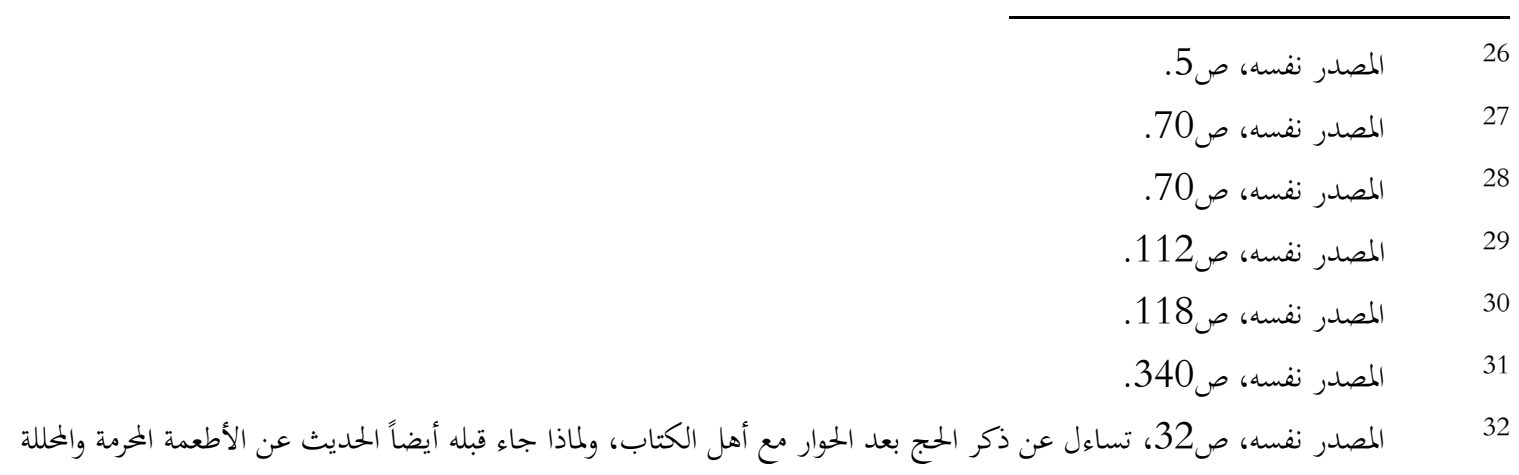


تفسير سورة النساء نصاً طويلا،33 ومن مصادره التي أشار إليها تفسير الشيخ محمد الطاهر بن عاشور التحرير والتنوير، وأيده فيما ذهب إليه من رأي: "وأنا أؤيد تفسير الفاضل 34 ابن عاشور"، 35 ونقل عنه أيضاً: "وقال ابن عاشور في تفسيره: إن اللقاء هنا الجهاد"، 36 وأخذ عنه كذلك رأيه في تفسير "الرق المنشور" في سورة الطور على أنه صحائف موسى: "وهذا رأي العلامة ابن عاشور"، 37 ووصفه هنا بالعلامة لتقديره لتفسيره وآرائه. وقد رأيت في منزله في قسنطينة تفسير ابن جزي الأندلسي التسهيل فسألته عنه، فأثنى عليه لإفادته واختصاره، ولكن لم يذكره، ولم ينقل عنه في تفسيره، ولعله لم يلمح فيه شيئاً جديداً.

وينبغي أن نشير فيما يتعلق بتفسير وحدة السورة الموضوعية إلى أنه ذكر تأسّيه بالدكتور الشيخ محمد عبد الله دراز في تفسيره لوحدة الموضوع في السورة الواحدة: "وتأسيت في ذلك بالشيخ محمد عبد الله دراز عندما تناول سورة البقرة وهي أطول سورة في القرآن، فجعل منها باقة واحدة ملونة نضيدة، يعرف ذلك من قرأ كتابه النبأ العظيم وهو أول تفسير موضوعي لسورة كاملة فيما أعتقد". 38 وأود هنا أن أذكر بعض الاجتهادات التي صرح أها اجتهاداته الخاصة، وأها فهم اهتدى إليه، أو معنى أوتيه أو اختاره من بين اجتهادات من تقدمه من المفسرين؛ من ذلك أنه يرى أن أصحاب الأعراف هم الدعاة والشهداء، وليسوا كما يرى المفسرون هم الذين استوت حسناقم وسيئاتم، 39 كذلك له اجتهاد في

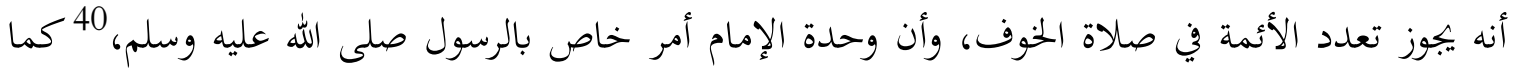
شك في رأي الجيولوجيين في تحديدهم لبداية الجنس البشري، وذهب إلى رأي غير رأيهم. 41 ويرى أن عيسى

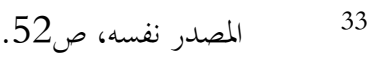

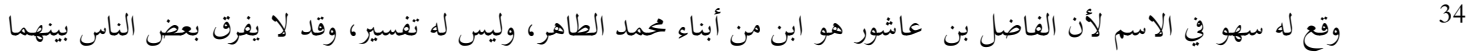

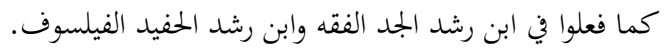

$$
\begin{aligned}
& 35 \\
& 36 \\
& 37 \\
& 38 \\
& 39
\end{aligned}
$$

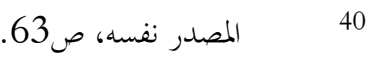

$$
\begin{aligned}
& 41
\end{aligned}
$$


عليه السلام جرت عليه سنة الموت فمات، وأن عودته إنما هي إحياء له من جديد؛42 وله اجتهاد خاص في سبب شيب الرسول صلى الله عليه وسلم من سورة هود، رآه في توجيه الخطاب إليه مباشرة خلال السورة مرات متعددة من أوها إلى آخرها، الأمر الذي لا يوجد في غيرها، 43 وذهب في تفسير يأجوج ومأجوج إلى أفم يعيشون في الصين، وأنه يبدو من جرس الكلمة أها صينية، 44 يخالفاً في ذلك ما ذهب إليه ابن عاشور

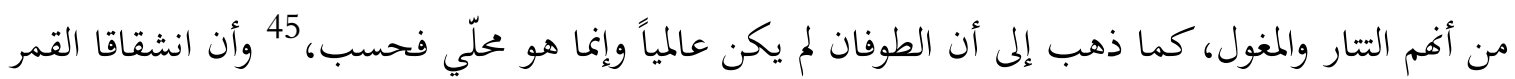
الذي ورد في فاتحة سورة القمر إنما هو انشقاق يقع في آخر الزمان حين تضطرب الأفلاك ويتغير نظام

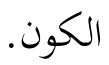

وله فهم خاص في "الشفق" الذي ورد في سورة الانشقاق: "وقد بجا لي فيه هذا القَسَم فهم إن كان حقاً فمن الله وله المنة، وإن كان خطأ فمن نفسي، وأسأله العفو: إن الشفق هنا إيماءة على تاريخ المسلمين، وما يعتريه من عسر ويسر، وهزيكة ونصر ... وقد جئنا في أصيل العالم أو في شفقه، والغروب موشك"، 46 وذهب إلى رأي المطلقة طلاقاً بائناً والنفقة عليها؛ 47 ولاحظ أن كلمة "القرآن" تكررت في سورة الإسراء نهو إحدى عشرة مرة، فبين السّر في ذلك، وهو أمر لم يسبق إليه فيما أعتقد: "إن سورة بني إسرائيل (الإسراء) انفردت بهذه الخاصة علّ المسلمين يفقهون أن القرآن الذي صنع أمتهم قديماً، قدير على أنه يصبّهم في قوالب السيادة والقيادة مرة أخرى...". 48 $-5-$

$$
\begin{aligned}
& 42 \\
& 43 \\
& 44 \\
& 45
\end{aligned}
$$

46 المصدر نفسه، ص507-508، يكسن الرجوع إلى المصدر لاستكمال الصورة وما ورد في ذلك من حديث رواه التمذي لما طالعه

$$
\text { الشيخ بدا له هذا المعنى التاريخي. }
$$


ومن أهم مواقف شيخنا التي عشتها معه وشاهدته فيها محاربته التي لا هوادة فيها لبعض من يزعمون أفم دعاة، ويسمى هذه الظاهرة "بالطفولة" أو "فتيان سوء"، 49 ويقرها "بالطفولة الشيوعية" التي نقدها لينين. ويبدو أن الذي دفعه إلى تأليف كتابه "السنة النبوية بين أهل الفقه وأهل الحديث" هو هذه الظاهرة الطفولية في الدعوة والفهم السقيم، والتعلق بالأحاديث وإن كانت أوهى من بيت العنكبوت، دون النظر إلى القرآن، وهو ما ينبغي أن يدرسوه أولاً، ولذلك قال في أول هذا الكتاب: "وفي هذا الكتاب جرعة قد تكون مرّة للفتيان الذين يتناولون كتب الأحاديث النبوية ثم يحسبون أفم أحاطوا بالإسلام علماً، بعد قراءة عابرة أو عميقة" 50 كما أن: "فيه درساً آخر لأولئك الذين يحاربون الفقه المذهبي ويركنون إلى سلفية مزعومة، عرفت من الإسلام قشوره، ونسيت جذوره"، 51 إذ إن "التقليد المذهبي أقل ضرراً من الاجتهاد الصبياني في فهم

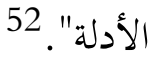

ومعنى هذا أن كتابه هذا صنعه لعلاج ما انتشر من فقه بدوي، وتصور طفولي للعقائد والشرائع، 53 وقد أدى هذا السلوك الذي ينظر إلى النقاب وتصير الجلباب نظرته إلى التوحيد، إلى تخويف الناس من الصحوة الإسلامية، ومكن الخصوم من بسط ألسنتهم 54 الحداد فيها، لا يفرقون في ذلك بين مستنير مستقيم الفكر والعمل، ومظلم معوج الفكر والعمل، وكأفم يريدون فيما يرى الشيخ الغزالي "نقل تقاليد عبس وذبيان إلى أمريكا"55 فيما يتعلق بالمرأة، فتجدهم "أرباب لحى"، وأصحاب هامات و قامات، يقعون على تلى أحاديث لا يفهموها ثم يقدمون صورة للإسلام تثير الانقباض والخوف.56 وتكمن وراء هذه القامات والهامات "عقلية طفولية" مخيفة تريد أن تقود الأمة إلى ظلام حالك. وهكذا تظهر في الميدان ظاهرة التدين

$$
\begin{aligned}
& \text { 49 } \\
& 50 \\
& 51 \\
& 52 \\
& 53 \\
& 54 \text { 5 } 55 \\
& 55 \\
& 56 \quad 5
\end{aligned}
$$


الفاسد التي تضم إلى الدين ما ليس منه، 57 ففشلوا في عرض الدين، وشوّهوا معالمه، وبذلك أصبحت الدعوة الدينية مهزومة في ميدان الإعلام. 58 فالتدين الفاسد يسلك سلوكاً غبياً، ويحسبه صاحبه من الإيمان بالغيب: "وقد رأيت في تحاربي أن الفرق بين تدين الشكل وتديُّن الموضوع هو قسوة القلب أو رقته، بعض الناس في طباعهم جلافة وقساوة، لا تخفيها صور العبادات التي يستهلون أداءها"، 59 وإذا قسا قلب من يزعم لنفسه قيادة الدعوة، فتلك هزيمة منكرة لا ناصر لها: "وقد لاحظ نقَدة الفكر الديني أن بعض الناس يقصر ثوبه دلالة تقوى، وفي قلبه كبر فرعون"، 60 ومقتضى الإيمان وفي صدورهم صلف وثرة، تستغرب قساوة قلوبكم، وخشونة جوانبهم"؛ 61 ويسمي هذه الظاهرة أيضاً التدين الجاهل حينما يعتقد أصحابه أن التخلف في الدنيا أمارة التقدم في الآخرة: 62 "وهذا فهم منكر، فإن الدخول إلى الإيمان يكون من باب العلم الحاذق، لا من باب القصور البليد"63 ولأن: "الفقه في الدنيا جزء من العقل الذي يفقه الآخرة، ولن يستطيع نصرَ الإيمان أبله ولا قاعد"،64 ويتساءل: "هل الفشل في الأرض هو طريق النجاح في السماء؟"65 ويرى أن هذا هو ما بـ أدى إلى فشل إدارة الأديان في الأرض، فإن الإيمان بالله يُنى -فيما يبنى عليه- على التأمل في الكون، ودراسة قوانينه؛66 ويصور التدين بأنه: "قوة وبصيرة وليس وهناً ولا غباءً"، 67 وهو معنى قرآني خالص، حينما يصف القرآن الأنبياء والرسل بأفم ذوو الأيدي والأبصار.

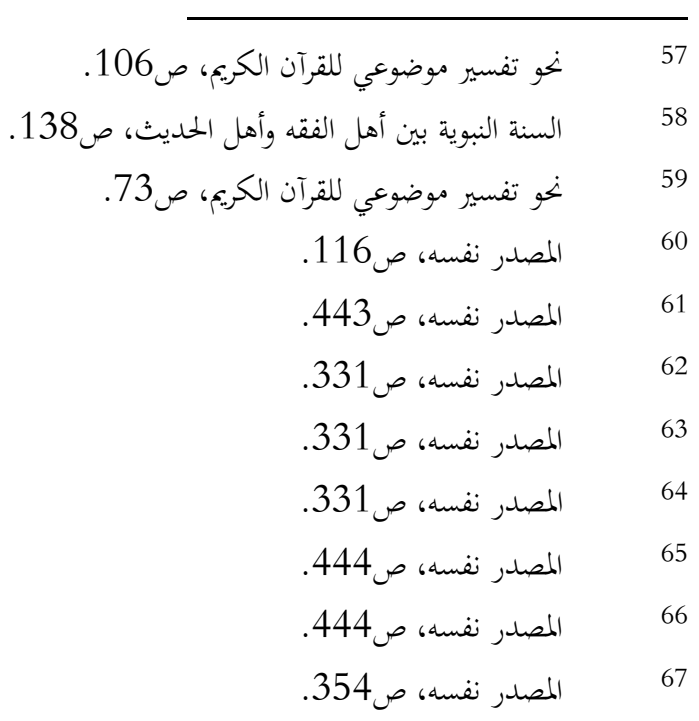


ويرى شيخنا أن: "نصف فساد العالم يرجع إلى قصور رجال الدين، وتبلدهم النفسي"، 68 وذلك

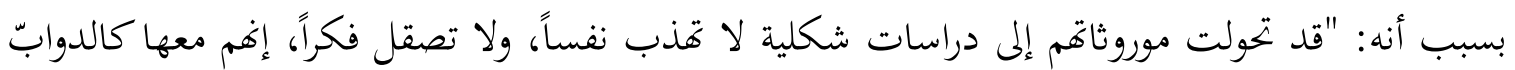
التي تحمل صناديق الكتب ولا صلة لها بما حوت"، 69 وينصح الشيخ الغزالي أنصاف المتعلمين وأنصاف المتدينين "بأن يسكتوا أو أن يستحيوا"70 إذا تكلموا في الإسلام، ولا علم لهم بالكتاب والسنة، ولا فهم.

إن علة انتشار الإلحاد والمادية إنما هي في نظره: "غياب الوحي الحق، لعجز حملته عن وعيه وتبليغه، وسيادة فلسفات وأديان أرضية، لا تشبع غمة العقل، ولا ترضي أشواق الفطرة". 71 ويتساءل الشيخ الغزالي: لماذا لا يتعلم هؤلاء الدين، ويحسنون فقهه والعمل به وعرضه؟: "فإن القادة لا تكون أقل مستوى من المقودين"؛72 وأنكى من ذلك كله وأدهى، أن يؤدي سوء الفهم، وسوء العمل إلى القتل والقتال، وسفك وهك دماء الأمة: "وفي هذه الأيام النحسات، شاعت الخنلافات في أرجاء الأمة وقتل بعضها بعضا، بل إن حصيلة القتلى في الفتن الداخلية أربى من القتلى في محاربة الاستعمار الصليبي العائد، المتحالف مع اليهود والناقمين".

هذا كله تحليل لأمراض الدعاة، وتشخيص لأدوائهم، ونتائج سوء أفهامهم وأعمالم في ضعف الأمة و وتاكلها.

ومن أهم أعماله التي عايشتها، وأفدتُ منها في حياتي الثقافية ما عالجه في أحاديثه وكتبه، وخاصة كتاب السنة النبوية بين أهل الفقه وأهل الحديث، من ظاهرة المرويات الواهية، ومملتها من ذوي العقليات الحرفية، ومنقطعي الصلة بفهم القرآن، وجعله مقياساً لما يقبل وما لا يقبل من الأحاديث، يصدرون الأحكام، ويرسلون الفتاوى، فيزيدون الأمة بلبلة وحيرة، ولا زلت أحذّر الأمة من أقوام بصرهم بالقرآن كليل،

$$
\begin{aligned}
& 68 \\
& 69 \\
& 70 \\
& 71 \\
& 72 \\
& 73
\end{aligned}
$$


وحديثهم عن الإسلام جريء، واعتمادهم كله على مرويات لا يعرفون مكاها من الكيان الإسلامي،

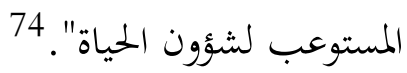

وكان شديد الحرص على: "شدة الانتباه إلى ألفاظ القرآن ومعانيه، فجملة غفيرة من أهل الحديث

محجوبون عنها، مستغرقون في شؤون أخرى، تعجزهم عن تشرب الوحي". 75

وقد انتشرت أحاديث بين الشباب يأخذون منها أحكاماً سيئة، إن قبل سندها افتراضاً، فإن متوفا لا يصح قبولا؛76 وهو يسلك في ذلك مسلك عمر بن الخطاب رضي الله عنه ومنهج أبي حنيفة في الأخذ بظاهر القرآن وعمومياته، وتقديم ذلك على أحاديث الآحاد، وتقديم الرأي القوي على الروايات المشكوك فيها. 77 ويقوم منهجه على منع التناقض بين القرآن والسنة أو فهمها على غير وجهها، ونفي التناقض بين ذلك كله، وبين الواقع التاريخي الثابت. 78 ولذلك فهو يرى أن "من لا فقه لهم يجب أن يغلقوا أفواههم لئلا يسيئوا إلى الإسلام، بحديث لم يفهموه، أو فهموه وكان ظاهر القرآن ضده" فيميدان التدين وكانت بضاعته في الحديث مزجاة بالذي يدخل السوق وليس معه إلا نقود مزيفة، 80 أو

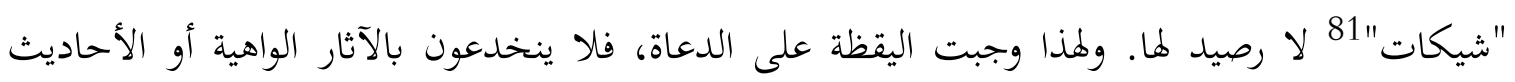
الموضوعة، وأن يعرفوا المعاني الصحيحة لما صح منها، فلا فقه بلا سنة، ولا سنة بلا فقه.

ومن المآسي التي نبه إليها "أننا نحن المسلمين مولعون بضم تقاليدنا وآرائنا إلى عقائد الإسلام وشرائعه، لتكون دينا مع الدين"، 82 وهذا ما أدى إلى مسالك معوجة، كما لا حظ الشيخ: "وقد رأيت في هذه الأيام من يسمي نفسه أمير جماعة، والجها الذي يبذله، يتصبب عرقاً وهو يقوم به، هو إشاعة النقاب بين النساء،

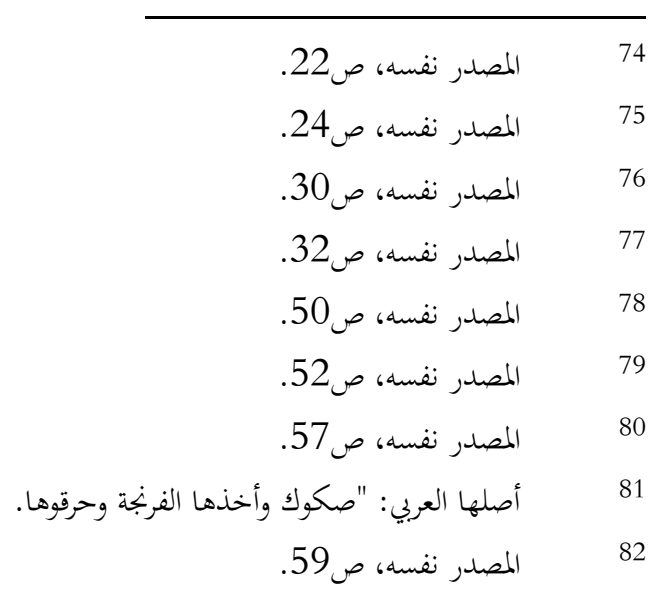


أو إشاعة الجلباب بين الرجال، أو تحريم الذهب على النساء و الرجال جميعا، أو ترك شعر اللحية ينمو فلا يؤخذ منه شيء حتى لقاء الله"، 83 حتى خيل لبعض الشباب المسكين: "أن الجلباب هو زي الإسلام، وأن البدلة زي الكفار"،84 فالإسلام ليس كما يتصوره هؤلاء "ديناً إقليمياً، ولا فقهاً بدوياً ضيق النطاق"، 85 ولعلهم يريدون أن يجعلوا مصدر الدين هو المجتمع وأنه ظاهرة اجتماعية تصدر عنه، كما زعم بعض علماء الاجتماع.

وأدى الجهل بالقرآن إلى القول بأن لأحاديث الآحاد تنسخ القرآن، وهو: "زعم في غاية الغثاثة"، 86 فكيف تترك آية لحديث هو موضع لغط. 87 وهناك مرويات واهية إذا أخذ بها أدت إلى خراب العالم، كالآثار التي تزهّد الزينة التي أخرج الله للناس في الدنيا: "لو جعلنا هذه المرويات محو حياة عامة لشاع الخراب في أرجاء الدنيا"، 88 ولو أن العالم الإسلامي اتبع هؤلاء الحرفيين لتراجع إلى العصر الحجري في بعض جوانبه. 89

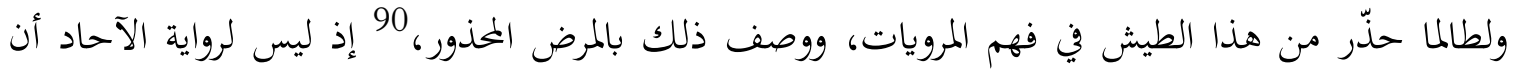
تشغب على الكتاب والسنة الثابتة، أو أن تعرّض حقائق الدين للتهم والريب والنفور؛91 ولا يصح أخذ رول الحكم الديني من حديث مفصول عن الأحاديث الأخرى، وعما دل عليه القرآن.

وخلاصة هذا الأمر عنده أن "القرآن هو الإطار الذي تعمل الأحاديث في نطاقه لا تعدوه، ومن زعم أن السنة تقضي على الكتاب أو تنسخ أحكامه فهو مغرور"،92 وهو في هذا يدفع الأحاديث الضعيفة والموضوعة أو المعلولة كما فعل غيره من المحدّثين، لما رآه من قافت الناس على هذه الواهيات والمعلولات التي

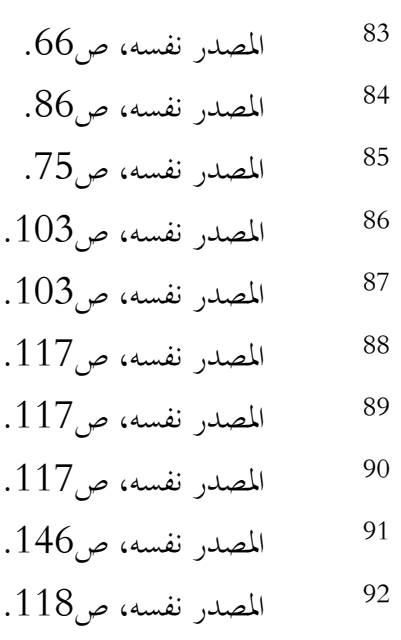


تتنافق مع القرآن، وأصول الدين. ونعى على جماعة من البطالين والفاشلين وقوفهم عندما هو مرفوض، وحسبوه ديناً ثابتاً، وما هو من الدين، كما نعى على القاصرين ممن يشتغلون بالحديث بلا معرفة بحقيقته، ثم يحلو لهم أن يشغبوا على الدين كله، بلا وعي ولا فقه، 93 فشاعت أحكام طائشة، وأفهام سقيمة أدت إلى فتن عمياء، ومسالك ضالة مضلة. $-6-$

ولم يفت شيخنا الغزالي أن ينقد نقداً شديداً مسالك الساسة المعوجة، واستبدادهم الهالك، كما نقد حملة الأقلام، وخدمة الحكام من الكتاب، وممن ينتسبون إلى الدين، وما يزينونه من أعمال الظلمة، وأن ينقد أيضاً الأيديولوجيات المختلفة الألوان والأشكال من قومية وشيوعية ورأسمالية واشتراكية وعلمانية ومادية، وأن ينقد الحضارة الغربية المعاصرة، وهذا أمر يطول الخوض فيه.

ولكن الذي وددت أن أختم به كلمتي هذه هو أن أتعرض لجانب نقدي ممتاز فاق فيه كل من تعرضوا له ألا وهو نقده لموقف المجتمعات الإسلامية من المرأة، وتحقيرهم لها وهي الأم والأخت والزوجة والبنت. فهو من أكثر الدعاة إنصافاً لها، وذوداً عن حياضها وكرامتها، فهو يرى أن المجتمع الإسلامي حكم على المرأة بالموت الأدبي والعلمي مما يدل على أها أمة أكلها الجهل والاعوجاج، وأن ما يقوم به المشاغبون على سفور المرأة، يتصرفون في قضايا المرأة تصرفاً يهز كيانا الروحي والثقافي والاجتماعي، 94 حتى إنه وُضع حديث وضعاً لا أصل له، يمنع المرأة من تعلم الكتابة. 95 وقد أنزلتها بعض الأوساط منزلة الكلب: "لاحظت في بعض الأوساط الهابطة أن المرأة عليها وليس لها، وأها تعامل بامتهان وغلظة، وأها قد تأكل الفضلات في البيت، وتذهب أطايب الطعام إلى غيرها، والسبب الأول بعض المتحدثين في الدين من الجاهلين

\begin{tabular}{|c|}
\hline المصدر نفسه، ص128. \\
\hline المصدر نفسه، ص41. \\
\hline
\end{tabular}


والتافهين"، 96 وذكر" "أن نفراً من المسلمين فارغي القلوب والعقول يحتقرون الأنوثة، ويهينون الزوجة والأخت والبنت، ويتقربون بحبسها وبتهيلها والاستطالة عليها". 97

ويأسف الشيخ الغزالي أن يرى "عدداً من المتدينين يبني تقواه على الإغلاظ للمرأة، وإساءة عشرقا، وانتقاص مكانتها، حتى كره النساء في العالم كله الإسلام، وخافوا من سيطرته على المجتمع مع هذا الفهم

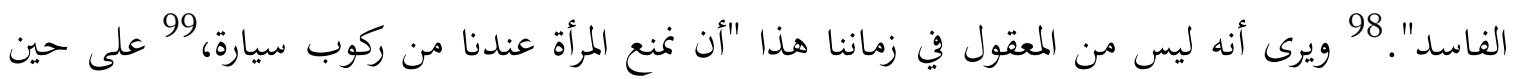
يعطيها العالم حق قيادة أمة، والسهر على مصالحها". 100 ويصف أولئك الذين يدافعون عن بقاء المرأة في الظلم بأفم أصحاب "غباوة رائعة"، 101 ولم أر لغيره من الكتاب هذا التعبير الساخر، فالمرأة ذات الدين عنده: "خير من ذي لحية كفور". 102 وينبه هؤلاء إلى أن امرأة يهودية: "شاركت في المزيمة المخزية التي نزلت بنا، وأقامت دولة إسرائيل على أشلائنا... وقادت قومها، وأذلت نفراً من الساسة العرب لهم لحى وشوارب في حرب الأيام الستة، وي حروب تالية"، 103 كما عاد المارشال يهيى خان يجر أذيال الحيبة إثر هزيكته أمام قيادة امرأة هندية: أنديرا غاندي 104 التي قصمت ظهر باكستان.

هذا ما أردت أن أعبر عنه، واخترت أن أنقل نصوصاً حرفية لشيخنا حتى لا يقال إني تقوّلت عليه أو سلكت في ذلك مسالك الخيال، والحمد لله رب العالمين.

$$
\begin{aligned}
& 96 \text { ن } \\
& 97 \text { 9 } 98 \\
& 98 \\
& 99 \\
& 100 \\
& 101 \\
& 102 \\
& 103 \\
& 104
\end{aligned}
$$

